\title{
Isolation of the bioactive peptides CCHamide-1 and CCHamide-2 from Drosophila and their putative role in appetite regulation as ligands for $\mathrm{G}$ protein-coupled receptors
}

\author{
Takanori Ida ${ }^{1}$, Tomoko Takahashi ${ }^{2}$, Hatsumi Tominaga' ${ }^{1}$,Takahiro Sato ${ }^{3}$, Hiroko Sano ${ }^{3}$, Kazuhiko Kume ${ }^{4}$, \\ Mamiko Ozaki ${ }^{5}$, Tetsutaro Hiraguchi ${ }^{5}$, Hajime Shiotani ${ }^{5}$, Saki Terajima ${ }^{5}$, Yuki Nakamura ${ }^{5}$, Kenji Mori $^{6}$, \\ Morikatsu Yoshida ${ }^{6}$, Johji Kato ${ }^{7}$, Noboru Murakami ${ }^{8}$, Mikiya Miyazato $^{6}$, Kenji Kangawa ${ }^{6}$ and \\ Masayasu Kojima ${ }^{3}$
}

${ }^{1}$ Interdisciplinary Research Organization, University of Miyazaki, Miyazaki, Japan

${ }^{2}$ Department of Biology, School of Medicine, Kurume University, Fukuoka, Japan

${ }^{3}$ Molecular Genetics, Institute of Life Sciences, Kurume University, Fukuoka, Japan

${ }^{4}$ Department of Stem Cell Biology, Institute of Molecular Embryology and Genetics, Kumamoto University, Kumamoto, Japan

${ }^{5}$ Department of Biology, Graduate School of Science, Kobe University, Hyogo, Japan

${ }^{6}$ Department of Biochemistry, National Cerebral and Cardiovascular Center Research Institute, Osaka, Japan

${ }^{7}$ Frontier Science Research Center, University of Miyazaki, Miyazaki, Japan

${ }^{8}$ Department of Veterinary Physiology, Faculty of Agriculture, University of Miyazaki, Miyazaki, Japan

\section{Edited by:}

Hubert Vaudry, University of Rouen,

France

\section{Reviewed by:}

Young-Joon Kim, Gwangju Institute of Science and Technology, South Korea Liliane Schoofs, Catholic University of Leuven, Belgium

Christian Wegener, Universität

Würzburg, Germany

*Correspondence:

Takanori Ida, Interdisciplinary

Research Organization, University of Miyazaki, Miyazaki 889-1692, Japan. e-mail: a0d203u@cc.miyazaki-u.ac.jp
There are many orphan G protein-coupled receptors (GPCRs) for which ligands have not yet been identified. One such GPCR is the bombesin receptor subtype 3 (BRS-3). BRS-3 plays a role in the onset of diabetes and obesity. GPCRs in invertebrates are similar to those in vertebrates. Two Drosophila GPCRs (CG30106 and CG14593) belong to the BRS-3 phylogenetic subgroup. Here, we succeeded to biochemically purify the endogenous ligands of Drosophila CG30106 and CG14593 from whole Drosophila homogenates using functional assays with the reverse pharmacological technique, and identified their primary amino acid sequences. The purified ligands had been termed CCHamide- 1 and $\mathrm{CCHamide-2,} \mathrm{although}$ structurally identical to the peptides recently predicted from the genomic sequence searching. In addition, our biochemical characterization demonstrated two $\mathrm{N}$-terminal extended forms of CCHamide-2. When administered to blowflies, CCHamide-2 increased their feeding motivation. Our results demonstrated these peptides actually present as the major components to activate these receptors in living Drosophila. Studies on the effects of CCHamides will facilitate the search for BRS-3 ligands.

Keywords: GPCR, novel bioactive peptide, Drosophila, CCHamide, bombesin receptor subtype 3

\section{INTRODUCTION}

G protein-coupled receptors (GPCRs) constitute a large protein superfamily that shares a 7 -transmembrane motif as a common structure. Human genome sequencing has identified several hundred orphan GPCRs for which ligands have not yet been identified (Vassilatis et al., 2003). GPCRs play crucial roles in cell-to-cell communication involved in a variety of physiological phenomena and are the most common target of pharmaceutical drugs. Therefore, the identification of endogenous ligands for orphan GPCRs will lead to clarification of novel physiological regulatory mechanisms and potentially facilitate the development of new GPCR-targeted therapeutics. Many bioactive molecules have been discovered or identified as endogenous ligands of orphan GPCRs through reverse pharmacology to date (Civelli et al., 2012). These molecules include nociceptin, prolactin-releasing peptide, orexin, apelin, ghrelin, metastin, and neuromedin S. The discovery of

Abbreviations: BRS-3, bombesin receptor subtype 3; GPCR, G protein-coupled receptors. novel endogenous ligands for orphan GPCRs in mammals is currently challenging, possibly because of the restricted timing of expression or distribution of GPCR ligands. One orphan receptor in mammals is the bombesin receptor subtype 3 (BRS-3). BRS3 is primarily expressed in the hypothalamus and plays a role in the onset of diabetes and obesity (Ohki-Hamazaki et al., 1997). Although several small molecules that are agonists and antagonists for BRS-3 have been synthesized, the native ligand of BRS-3 has not yet been identified (Majumdar and Weber, 2012).

The recent sequencing of the Drosophila melanogaster genome has enabled the identification of at least 160 fly GPCRs (Brody and Cravchik, 2000). Drosophila is an excellent animal model for genetic analysis of developmental and behavioral processes, as it is a small, genetically modifiable organism with a relatively short lifecycle and can be bred easily under laboratory conditions. Structural or sequence comparison of newly discovered peptides in Drosophila with candidate molecules in mammals may lead to the discovery of new peptide signaling modules. We recently reported the discovery of dRYamide-1, dRYamide-2, and trissin as ligands 
for Drosophila orphan GPCRs (Ida et al., 2011a,b). We consider it likely that additional novel bioactive peptides can be discovered for orphan GPCRs. Two Drosophila GPCRs (CG14593 and CG30106) belong to the BRS-3 phylogenetic subgroup (Hewes and Taghert, 2001).

Here, we report the identification of CCHamide- 1 and CCHamide-2, which are ligands for GPCRs CG30106 and CG14593, respectively, in D. melanogaster. Injection of CCHamide-2 resulted in the stimulation of feeding motivation in blowflies. These bioactive peptides may provide new insights in the search for BRS-3 ligands and the elucidation of D. melanogaster feeding mechanisms.

\section{MATERIALS AND METHODS}

\section{PURIFICATION OF Drosophila CCHamide-1 AND CCHamide-2}

An assay system using CG30106- or CG14593-expressing cells was prepared as previously described (Ida etal., 2011a,b). The fulllength cDNA of Drosophila CG30106 (GenBank accession number: NM_136355; residues -31 to 1700) and CG14593 (GenBank accession number: NM_136355; residues 656-2185) was obtained by RT-PCR using Drosophila cDNA as the template. The sense and antisense primers for CG30106 were $5^{\prime}$-aaatcgagcggactcagtacat$3^{\prime}$ and $5^{\prime}$-gtggcctgtaattcctgtaaactc- $3^{\prime}$, respectively. The sense and antisense primers for CG14593 were $5^{\prime}$-tgagacatcttgcccaggag$3^{\prime}$ and $5^{\prime}$-gtgtttcggtacctccatttat- $3^{\prime}$, respectively. The amplified cDNA was ligated into the pcDNA3.1 vector (Invitrogen). The expression vector, i.e., CG30106 or CG14593-pcDNA3.1, was transfected into Chinese hamster ovary $(\mathrm{CHO})$ cells by using with Fugene6 transfection reagent (Roche), and stably expressing cells were selected using $1 \mathrm{mg} / \mathrm{ml} \mathrm{G} 418$. The selected cell line, i.e., CHO-CG30106-line 2-4 or CHO-CG14593-line 10-1, showed the highest expression of CG3106 or CG14593 mRNA, respectively. Cells were cultured in a humidified environment of $95 \%$ air and $5 \% \mathrm{CO}_{2}$. Changes in intracellular $\mathrm{Ca}^{2+}$ concentrations $\left(\left[\mathrm{Ca}^{2+}\right]_{\mathrm{i}}\right)$ were measured using the FlexStation 3 fluorometric imaging plate reader to conduct high-throughput measurements of intracellular $\mathrm{Ca}^{2+}$ concentration (Molecular Devices, CA, USA; Marshall et al., 2005). CHO-CG30106 or CHO-CG14593 cells $\left(3 \times 10^{4}\right.$ cells) were plated into 96-well black-wall microplates (Corning, NY, USA) $20 \mathrm{~h}$ before each assay. The cells were incubated with $100 \mu \mathrm{l}$ of Calcium 4 assay kit reagent (Molecular Devices) for $1 \mathrm{~h}$, and then $50 \mu \mathrm{l}$ of each sample was added to the CHO-CG30106 or CHO-CG14593 cells to induce changes in fluorescence. The maximum $\left[\mathrm{Ca}^{2+}\right]_{\mathrm{i}}$ changes were recorded.

Drosophila melanogaster flies (Canton S.; $350 \mathrm{~g}$ ) were collected on dry ice. The whole body of each fly was boiled for $10 \mathrm{~min}$ in 10 volumes of water to inactivate intrinsic proteases. The solution was adjusted to $1 \mathrm{M} \mathrm{AcOH}$. Peptides were extracted by homogenization using a Polytron mixer. The supernatant of the extracts, obtained after $30 \mathrm{~min}$ of centrifugation at 11,000 rpm, was concentrated to approximately $1 / 10$ by an evaporator. The residual concentrate was subjected to acetone precipitation using $66 \%$ acetone. After the precipitates were removed, the supernatant acetone was evaporated and loaded onto a 40-g cartridge of Sep-Pak C18 (Waters), which was pre-equilibrated with $0.1 \%$ trifluoroacetic acid (TFA). The Sep-Pak cartridge was washed with $10 \% \mathrm{CH}_{3} \mathrm{CN} / 0.1 \% \mathrm{TFA}$, and then eluted with $60 \% \mathrm{CH}_{3} \mathrm{CN} / 0.1 \%$
TFA. The eluate was evaporated and lyophilized. The residual materials were redissolved in $1 \mathrm{M} \mathrm{AcOH}$ and then adsorbed on a column of SP-Sephadex C- $25\left(\mathrm{H}^{+}\right.$form $)$that had been pre-equilibrated with $1 \mathrm{M}$ AcOH. Successive elutions with $1 \mathrm{M}$ $\mathrm{AcOH}, 2 \mathrm{M}$ pyridine, and $2 \mathrm{M}$ pyridine- $\mathrm{AcOH}$ ( $\mathrm{pH}$ 5.0) provided three fractions of SP-I, SP-II, and SP-III. A basic peptide fraction (SP-III) was fractionated on a Sephadex G-50 gel filtration column $(2.9 \mathrm{~cm} \times 142 \mathrm{~cm}$; GE Healthcare, Tokyo, Japan $)$. A portion of each fraction, equivalent to $1.16 \mathrm{~g}$ of flies, was subjected to the assay using CHO-CG30106 or CHO-CG14593 cells. The active fraction was separated by carboxymethyl (CM)-ionexchange high-performance liquid chromatography (HPLC) on a TSK CM-2SW column $(4.6 \mathrm{~mm} \times 250 \mathrm{~mm}$; Tosoh, Tokyo, Japan) with an ammonium formate $\left(\mathrm{HCOONH}_{4} ; \mathrm{pH}\right.$ 6.5) gradient of $10 \mathrm{mM}$ to $1 \mathrm{M}$ in the presence of $10 \%$ acetonitrile $(\mathrm{ACN})$ at a flow rate of $1 \mathrm{ml} / \mathrm{min}$ for $160 \mathrm{~min}$. The active fractions were separated by reverse-phase (RP)-HPLC with a $\mu$ Bondasphere C18 column $(3.9 \mathrm{~mm} \times 150 \mathrm{~mm}$, Waters, MA, USA) by using a $10-60 \%$ ACN/ $0.1 \%$ TFA linear gradient at a flow rate of $1 \mathrm{ml} / \mathrm{min}$ for $80 \mathrm{~min}$. The active fractions were further purified by RP-HPLC using a diphenyl column $(2.1 \mathrm{~mm} \times 150 \mathrm{~mm}$, 219TP5125; Vydac, Hesperia, CA, USA) for $80 \mathrm{~min}$ by using a linear gradient of $10-60 \%$ ACN $/ 0.1 \%$ TFA at a flow rate of $0.2 \mathrm{ml} / \mathrm{min}$. Fractions corresponding to absorption peaks were collected, and an aliquot of each fraction (2 $\mathrm{g}$ tissue equivalent) was assayed by using the FLEX system. The active fractions were further purified by RP-HPLC by using a Chemcosorb 3ODSH column $(2.1 \mathrm{~mm} \times 75 \mathrm{~mm}$; Chemco, Osaka, Japan) for 80 or 160 min by using a linear gradient of $10-60 \% \mathrm{ACN} / 0.1 \%$ TFA at a flow rate of $0.2 \mathrm{ml} / \mathrm{min}$. Fractions corresponding to absorption peaks were collected, and an aliquot of each fraction ( $2 \mathrm{~g}$ tissue equivalent) was assayed by using the FLEX system. Approximately $20 \mathrm{pmol}$ of the final purified peptides was analyzed using a protein sequencer (model 494; Applied Biosystems, CA, USA), and approximately 1 pmol of each active fraction was subjected to determination of molecular weight by matrix-assisted laser desorption-ionization time of flight (MALDI-TOF) mass spectrometry by using a Voyager-DE PRO instrument (Applied Biosystems).

\section{CLONING OF Drosophila PREPRO-CCHamide-1 AND CCHamide-2 cDNA}

A tBLASTn search of the Drosophila genome resources was performed by using sequence of the purified peptides, and we obtained D. melanogaster mRNA sequences [CG14358 (CCHamide-1), NM_001104314; and CG14375 (CCHamide-2), NM_142028] derived from an annotated genomic sequence. We searched for open reading frames upstream and downstream of the genome sequences of CCHamide- 1 and CCHamide- 2 by using specific primers $5^{\prime}$-cgtgcagcttgcgaaataata- $3^{\prime}$ and $5^{\prime}$-cttctggcttagctagcgtgttatc- $3^{\prime}$ for CCHamide- 1 and $5^{\prime}$-caccagccaagtgcaagtatc $-3^{\prime}$ and $5^{\prime}$-cggtttttaatgtacgttgtgg- $3^{\prime}$ for CCHamide- 2 . The candidate PCR product was subcloned into the pCR-II TOPO vector and sequenced. The nucleotide sequence of the isolated cDNA fragment was determined by automated sequencing (DNA sequencer model 3100; Applied Biosystems) according to the protocol for the BigDye terminator cycle sequencing kit (Applied Biosystems). 


\section{PEPTIDES}

CCHamide-1 (SCLEYGHSCWGAH-NH ${ }_{2}$ ), CCHamide-2 (GCQAYGHVCYGGH-NH$H_{2}$ ), CCHamide-1 C-terminal free (SCLEYGHSCWGAH), CCHamide-2 C-terminal free (GCQAYGHVCYGGH), long-form CCHamide-2 (AQQSQAKKGCQAYGHVCYGGH-NH$H_{2}$ ), and long-form CCHamide-2 C-terminal free (AQQSQAKKGCQAYGHVCYGGH) were synthesized by Peptide Institute Inc. (Osaka, Japan).

\section{PROBOSCIS EXTENSION REFLEX TEST FOR APPETITE MEASUREMENT}

The proboscis extension reflex (PER) test and feeding test were performed for the blowfly Phormia regina as previously described (Nisimura et al., 2005; Ida et al., 2011a). CCHamide-2 was dissolved in blowfly linger solution at a concentration of $10 \mathrm{p \mu ol} / \mathrm{ml}$. Twenty flies were secured by their wings using washing pins, and the first PER test was performed by using 12 steps of sucrose concentrations that had been prepared by twofold serial dilutions in distilled water, beginning from a sucrose concentration of $1 \mathrm{M}$. We investigated the PER in three different groups of 20 flies each: no injection, fly linger injection, and fly linger plus peptide injection. The PER tests were performed 30 min after $1 \mu$ l of blowfly linger solution with or without peptide was injected into the shoulder of each fly. We repeated five sets of PER tests each, in which 20 flies were used in each batch.

\section{STATISTICAL ANALYSIS}

Results are presented as the mean \pm SEM for each group. To compare the PER thresholds among the three groups, we used a non-parametric Steel-Dwass test. The criterion for statistical significance was $p<0.05$ for all tests. The statistical software program GraphPad PRISM (GraphPad software, CA, USA) was used for analyses.

\section{RESULTS}

\section{STRUCTURAL DETERMINATION OF CCHamide-1 FOR CG30106}

$\left[\mathrm{Ca}^{2+}\right]_{\mathrm{i}}$ assays were performed by using the gel filtration samples to isolate the endogenous ligands of CG30106 (Figure 1A). The active fractions were observed in eight sequential fractions (numbers 48-55). The fractions (51-55) with particularly high activity were separated by CM-ion-exchange HPLC at $\mathrm{pH}$ 6.5. The active fractions were separated by RP-HPLC. The active fraction was purified as a single peak in the final RP-HPLC (Figure 1B, P1). The amino acid sequence of the purified peptide was determined as SXLEYGHSXWGAH ( $\mathrm{P} 1$; where $\mathrm{X}$ is a position that was not identified) using a protein sequencer. To elucidate the complete amino acid sequence of this peptide, Drosophila cDNA encoding the purified peptides was isolated by RT-PCR. The cDNA encoded a 182-residue protein (CG14358; Figure 1C) that contained features characteristic of an $\mathrm{N}$-terminal signal peptide immediately preceding the purified peptide sequence. Every $\mathrm{X}$ residue was a cysteine, and the rest of the sequence was identical to that determined by peptide sequencing (Figure 1C). Sequencing resulted in a very low yield of phenyl thiohydantoin (PTH) at the steps involving $\mathrm{X}$, which suggests that two cysteines may form disulfide bonds ( $\mathrm{S}-\mathrm{S}$ bonds). The preproprotein contained a potential processing site at the $\mathrm{C}$-terminal end of the purified peptide sequence. This peptide contained Gly residues that presumably serve as an amide donor for C-terminal amidation. We therefore deduced the primary structure of the peptide to be SCLEYGHSCWGAH-NH 2 . This peptide had been named CCHamide-1 (Roller et al., 2008). Mass spectrometric analysis revealed that the observed monoisotopic $m / z$ value of the purified peptide (1445.30) was very similar to the theoretically predicted value for this peptide (1445.55) when including an intrachain disulfide bond and C-terminal amidation. We generated the synthetic peptide SCLEYGHSCWGAH-NH (CCHamide-1). The retention time of the $\mathrm{P} 1$ active fraction was identical to that of the synthetic SCLEYGHSCWGAH-NH peptide (which has an intrachain disulfide bond) on RP-HPLC (Figure 1D). Thus, these data suggest that both natural peptides have an intrachain disulfide bond and C-terminal amidation. Figure 1E shows the active fractions of each chromatography and the amino acid sequence of CCHamide- 1 .

\section{STRUCTURAL DETERMINATION OF CCHamide-2 FOR CG14593}

The endogenous ligands of CG14593 were isolated in the same manner as those of CG30106 (Figure 2A). Three separate active fractions were revealed (Figure 2G, P2, P3, and P4), and each active fraction was purified as a single peak in the final RPHPLC (Figures 2B-D). From the results obtained by using a protein sequencer and Drosophila cDNA encoding the purified peptides (Figure 2E), we deduced the primary structure of the peptide to be AQQSQAKKGCQAYGHVCYGGH-NH $\mathrm{N}_{2}(\mathrm{P} 2)$, GCQAYGHVCYGGH-NH ${ }_{2}$ (P3), and KKGCQAYGHVCYGGH$\mathrm{NH}_{2}$ (P4; Figure 2G). All of these cysteines may form S-S bonds. The shortest peptide (P3) had been named CCHamide-2. The cDNA encoded a 136-residue protein (CG14375; Figure 2E) that contained features characteristic of an N-terminal signal peptide immediately preceding the purified longest peptide sequence (P2). All peptides were derived from the same precursor (CG14375), but the length of the N-terminal peptide was different. Mass spectrometric analysis revealed that the observed monoisotopic $m / z$ values of the purified peptides (P2, 2216.80; P3, 1347.69; and P4, 1603.60) were similar to the theoretically predicted values $(2216.99,1347.52$, and 1603.71, respectively) for a peptide that has an intrachain S-S bonds and C-terminal amidation. We generated the synthetic peptides AQQSQAKKGCQAYGHVCYGGH-NH $\mathrm{N}_{2}$ (long-form CCHamide2) and GCQAYGHVCYGGH-NH$H_{2}$ (CCHamide-2). The retention times of the $\mathrm{P} 2$ and $\mathrm{P} 3$ active fractions were identical to those of the synthetic AQQSQAKKGCQAYGHVCYGGH-NH and GCQAYGHVCYGGH-NH 2 peptides (which have an intrachain disulfide bond) on RP-HPLC, respectively (Figure 2F). Thus, these data suggest that both natural peptides have an intrachain disulfide bond and C-terminal amidation.

\section{PHARMACOLOGICAL CHARACTERIZATION}

The interaction of CCHamide-1 and CCHamide-2 with CG30106 or CG14593 was examined using synthetic peptides. CCHamide-1 induced concentration-dependent, robust increases in $\left[\mathrm{Ca}^{2+}\right]_{\mathrm{i}}$ in CHO-CG30106 cells, with a half-maximal response concentration $\left(\mathrm{EC}_{50}\right)$ of $1.80 \times 10^{-11} \mathrm{M}$ (Figure $\left.3 \mathrm{~A}\right)$. CCHamide-2 potently activated CG30106 $\left(\mathrm{EC}_{50} ; 4.86 \times 10^{-9} \mathrm{M}\right.$ (Figure 3A). CCHamide-2 induced dose-dependent, robust increases in $\left[\mathrm{Ca}^{2+}\right]_{i}$ in $\mathrm{CHO}-$ CG14593 cells, with an $\mathrm{EC}_{50}$ of $4.80 \times 10^{-11} \mathrm{M}$ (Figure 3B). 


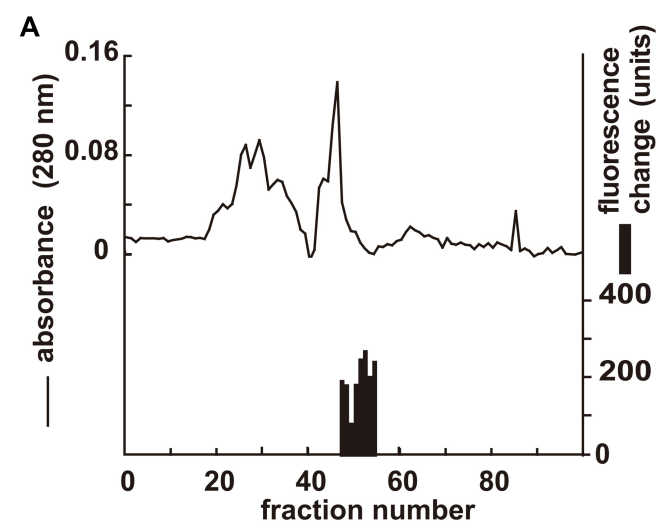

C

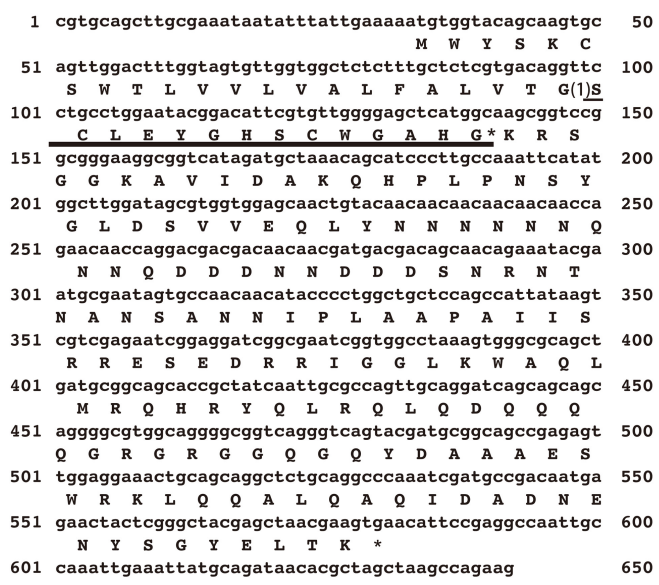

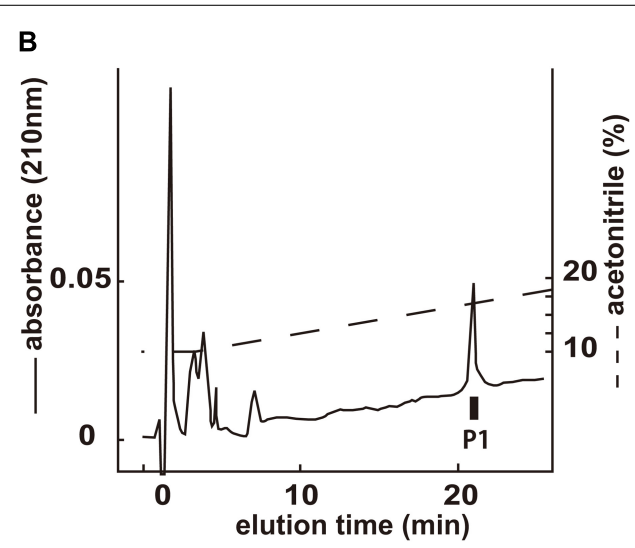

D

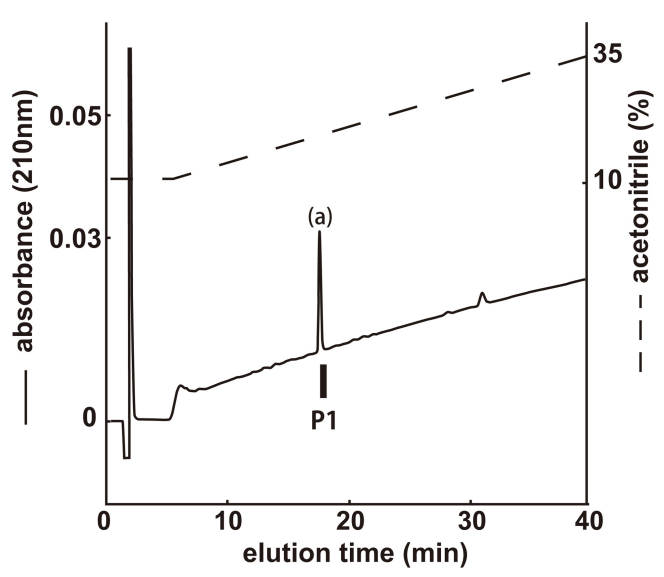

E

\begin{tabular}{|c|c|c|c|c|}
\hline gel filtration & $\begin{array}{c}\text { ion-exchange-HPLC } \\
\text { (ammonium formate }: \mathrm{mM})\end{array}$ & $\begin{array}{c}\text { reverse-phase-HPLC } \\
\text { (acetonitrile }: \%)\end{array}$ & sequence \\
\hline fr51-55 & $\begin{array}{c}\mathrm{fr} 23-24 \\
(171-191 \mathrm{mM})\end{array}$ & $\begin{array}{c}\text { fr31-32 } \\
(19.4-20.0 \%)\end{array}$ & $\mathrm{P} 1$ & SCLEYGHSCWGAH-NH2 \\
\hline
\end{tabular}

FIGURE 1 | Purification of CCHamide-1 from fly extracts. Black bars indicate changes of $\left[\mathrm{Ca}^{2+}\right]_{i}$ fluorescence signal in $\mathrm{CHO}-\mathrm{CG} 30106$ cells. (A) G-50 gel filtration of the SP-III fraction of fly extracts. The active fraction was subjected to one step of CM-ion-exchange HPLC and three steps of RP-HPLC. (B) Final purification of the active fraction by RP-HPLC. (C) Nucleotide sequence and deduced amino acid sequence of CCHamide-1 cDNA. CCHamide-1 cDNA encode 182-residue peptides. The asterisk indicates a glycine residue that serves as an amide donor for C-terminal amidation. The
CCHamide-1 sequence is underlined as (1). (D) Chromatographic comparison by RP-HPLC of natural CCHamide- 1 and synthetic CCHamide-1. Black bar (P1) indicates the changes of $\left[\mathrm{Ca}^{2+}\right]_{i}$ fluorescence signal in $\mathrm{CHO}-\mathrm{CG} 30106$ cells. Each peptide was applied to a Symmetry C18 column $(3.9 \mathrm{~mm} \times 150 \mathrm{~mm}$, Waters, MA, USA) with a 10-60\% ACN/0.1\% trifluoroacetic acid (TFA) linear gradient at a flow rate of $1 \mathrm{ml} / \mathrm{min}$ for $80 \mathrm{~min}$. P1 represent active fraction containing natural CCHamide-1. (a) Synthetic CCHamide-1. (E) Active fractions of each chromatography and the amino acid sequence of CCHamide-1.
CCHamide-1 potently activated CG14593 $\left(\mathrm{EC}_{50} ; 3.32 \times 10^{-8} \mathrm{M}\right.$ (Figure 3B). Neither CCHamide-2 nor CCHamide-1 induced a response in $\mathrm{CHO}$ cells transfected with the vector alone (data not shown). In the investigation of the interaction between non-Cterminal amidated synthetic peptides or long-form CCHamide-2 and CG30106, the $\mathrm{EC}_{50}$ values were as follows: non-C-terminal amidated CCHamide-1, $1.66 \times 10^{-10} \mathrm{M}$; non-C-terminal amidated long-form CCHamide-2, $8.93 \times 10^{-8} \mathrm{M}$; long-form CCHamide-2, $6.45 \times 10^{-8} \mathrm{M}$; and non-C-terminal amidated CCHamide-2, $1.22 \times 10^{-7} \mathrm{M}$ (Figure 3C). For CG14593, the $\mathrm{EC}_{50}$ values were as follows: long-form CCHamide-2, $1.49 \times 10^{-10} \mathrm{M}$; non-C-terminal amidated long-form CCHamide-2, $1.18 \times 10^{-9} \mathrm{M}$; non-C-terminal amidated CCHamide2, $1.13 \times 10^{-8} \mathrm{M}$; and non-C-terminal amidated CCHamide-1, $1.02 \times 10^{-7} \mathrm{M}$ (Figure 3D).

\section{PER TEST FOR MEASURING FEEDING SENSITIVITY}

As shown in Figure 4, a significant decrease was observed in the mean PER threshold, which was defined as the sucrose concentration at which $50 \%$ of flies show PER, after the injection of $10 \mathrm{pmol}$ 
A

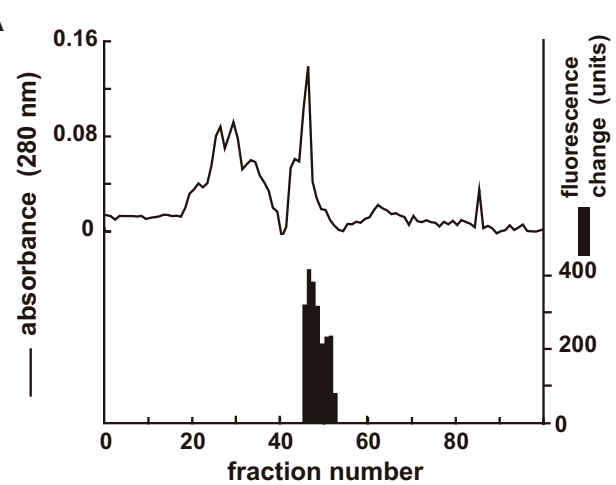

C

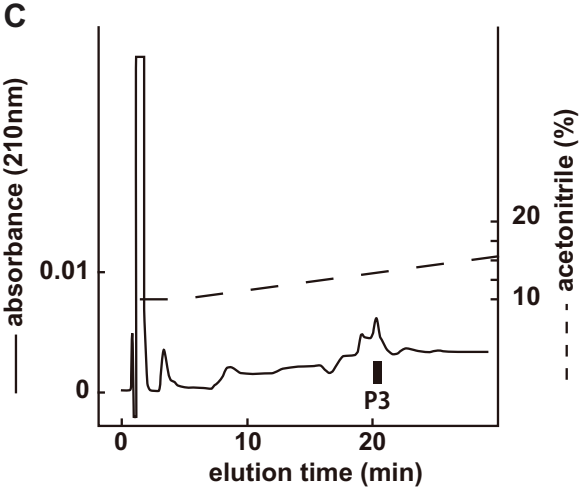

E

1 caccagccaagtgcaagtatcatgaaatccaccatatctttgctactggt 50

51 cgttatctgcaccgtggtcctggccgcgcaacagagccaagcgaaaaagg 100

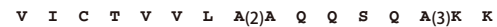

101 gatgccaggcctacggtcatgtgtgctacggtggtcatggcaagcgctct 150

(4)G $\begin{array}{llllllllllllllllllll}C & Q & A & Y & G & H & V & C & Y & G & G & H & G * & K & R & S\end{array}$

151 ctgagccccggatccgggtctggaacgggagtgggcgggggaatgggcga 200

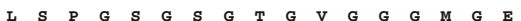

201 ggcagcctccgggggggcaggaaccggactatgtgcgtccgaatggectac 250

$\begin{array}{lllllllllllllllll}\text { A } & \text { A } & S & G & G & Q & E & P & D & Y & \text { V } & R & P & \text { N } & G & \text { L }\end{array}$

251 tgcccatgatggegccaaatgaacaggtgccgctcgagggcgactttaat 300

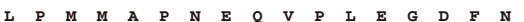

301 gactatcccgcccgtcaggtgctttacaaaatcatgaaatcatggtttaa 350

$\begin{array}{lllllllllllllllll}D & Y & P & A & R & Q & V & \text { L } & \text { Y } & \text { K } & \text { I } & \text { M } & \text { K } & S & \text { W } & \text { F } & \text { N }\end{array}$

351 ccgacctcgcegaccegcetctcgcctgggtgaacttgattatcccttgg 400

$\begin{array}{lllllllllllllllll}R & P & R & R & P & A & S & R & L & G & E & L & D & Y & P & L\end{array}$

401 ccaattccgccgaattgaatggcgtgaactaaggccggaaaagttatcaa 450

$\begin{array}{llllllllllllllll}\text { A } & \text { N } & S & \text { A } & \mathbf{E} & \mathbf{L} & \mathbf{N} & \mathbf{G} & \mathbf{V} & \mathbf{N} & \text { * }\end{array}$

451 tacagaaatatccacaacgtacattaaaaaccg 500

G

\begin{tabular}{|c|c|c|c|c|}
\hline \multirow{3}{*}{ gel filtration } & $\begin{array}{c}\text { ion-exchange-HPLC } \\
\text { (ammonium formate }: \mathrm{mM})\end{array}$ & $\begin{array}{c}\text { reverse-phase-HPLC } \\
\text { (acetonitrile : \%) }\end{array}$ & sequence \\
\hline \multirow{3}{*}{ fr47-50 } & $\begin{array}{c}\mathrm{fr} 38-41 \\
(322-362 \mathrm{mM})\end{array}$ & $\begin{array}{c}f r 15-16 \\
(14.4-15.0 \%)\end{array}$ & $\mathrm{P} 2$ & AQQSQAKKGCQAYGHVCYGGH-NH2 \\
\cline { 2 - 5 } & $\begin{array}{c}\mathrm{fr} 17-18 \\
(15.0-15.6 \%)\end{array}$ & $\mathrm{P} 3$ & GCQAYGHVCYGGH-NH2 \\
\cline { 2 - 5 } & $\begin{array}{c}\mathrm{fr} 15-16 \\
(14.4-15.0 \%)\end{array}$ & $\mathrm{P} 4$ & KKGCQAYGHVCYGGH-NH2 \\
\hline
\end{tabular}
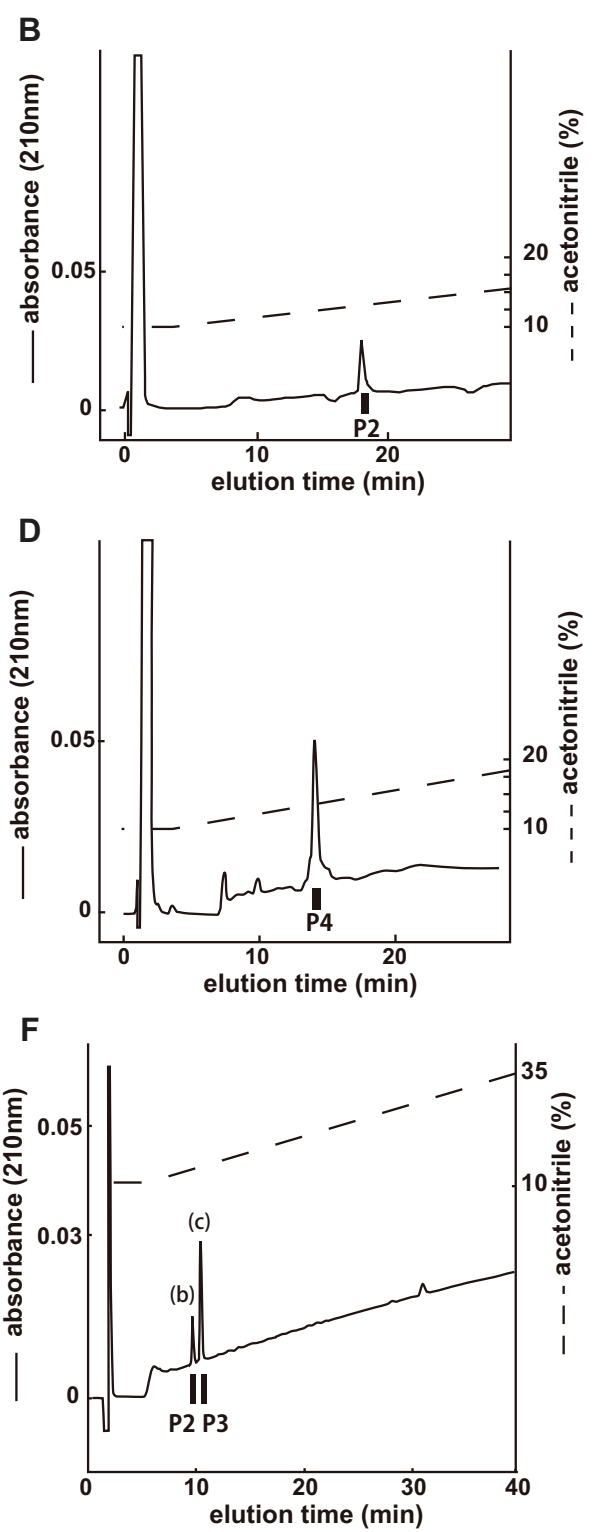

FIGURE 2 | Purification of CCHamide-2 from fly extracts. Black bars indicate changes of $\left[\mathrm{Ca}^{2+}\right]_{i}$ fluorescent signal in $\mathrm{CHO}-\mathrm{CG} 14593$ cells. (A) G-50 gel filtration of the SP-III fraction of fly extracts. The active fraction was subjected to one step of CM-ion-exchange HPLC and three steps of RP-HPLC. (B-D) Final purification of the active fraction by RP-HPLC. (E) Nucleotide sequence and deduced amino acid sequence of CCHamide-2 cDNA. CCHamide-2 cDNA encodes a 136-residue peptides. The asterisk indicates a glycine residue that serves as an amide donor for C-terminal amidation. The CCHamide-2 sequence is underlined as (4).
The other long-form of CCHamide-2 is translated from (2) or (3). (F) Chromatographic comparison by RP-HPLC of natural CCHamide-2 and synthetic CCHamide-2. Black bars (P2, P3) indicate the changes of $\left[\mathrm{Ca}^{2+}\right]_{i}$ fluorescence signal in $\mathrm{CHO}-\mathrm{CG} 14593$ cells. Each peptide was applied to a Symmetry C18 column with a linear gradient elution for $80 \mathrm{~min}$. P2 and P3 represent active fractions containing natural CCHamide-2. (b) Synthetic long-form of CCHamide-2. (c) Synthetic CCHamide-2. (G) Active fractions of each chromatography and the amino acid sequence of cCHamide-2. 

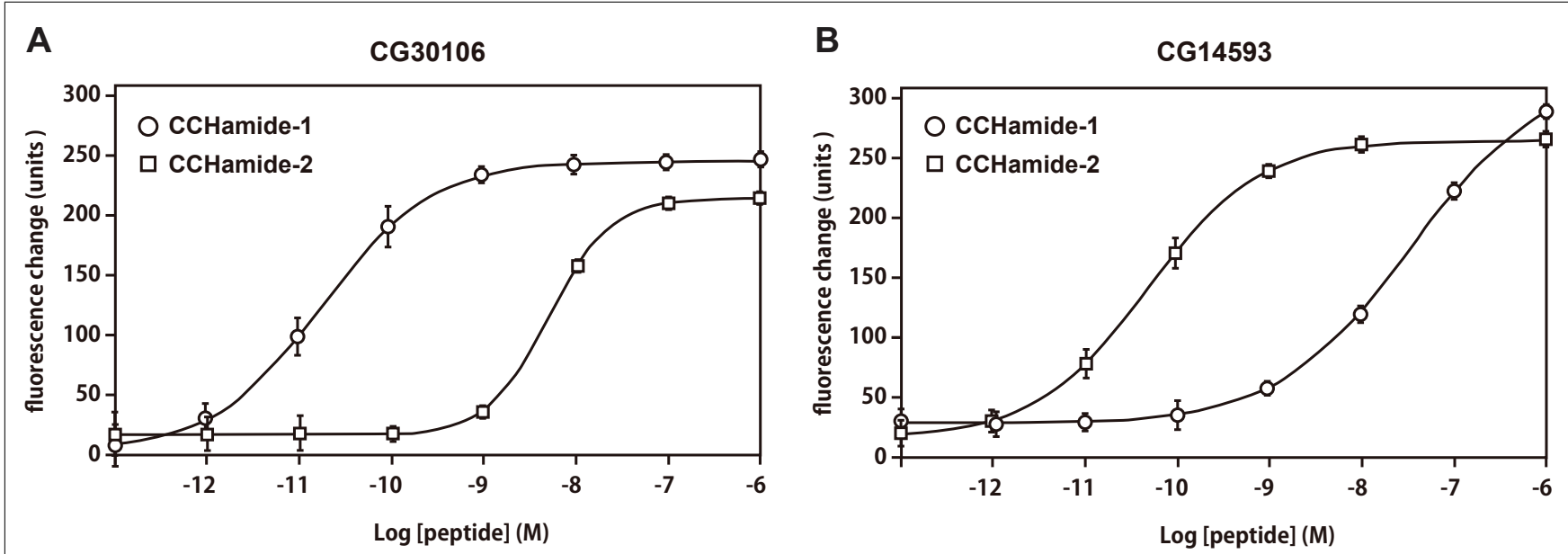

C

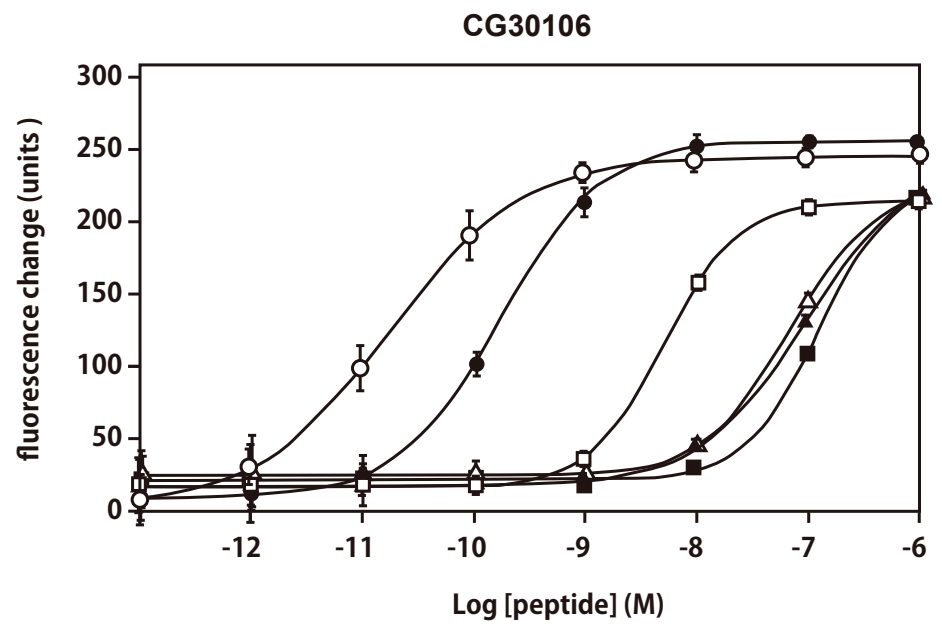

O CCHamide-1

Non-C-terminal

amidated CCHamide-1

$\square$ CCHamide-2

Non-C-terminal

amidated CCHamide-2

$\Delta$ long form CCHamide-2

$\Delta$ Non-C-terminal amidated

long form CCHamide-2

D

CG14593

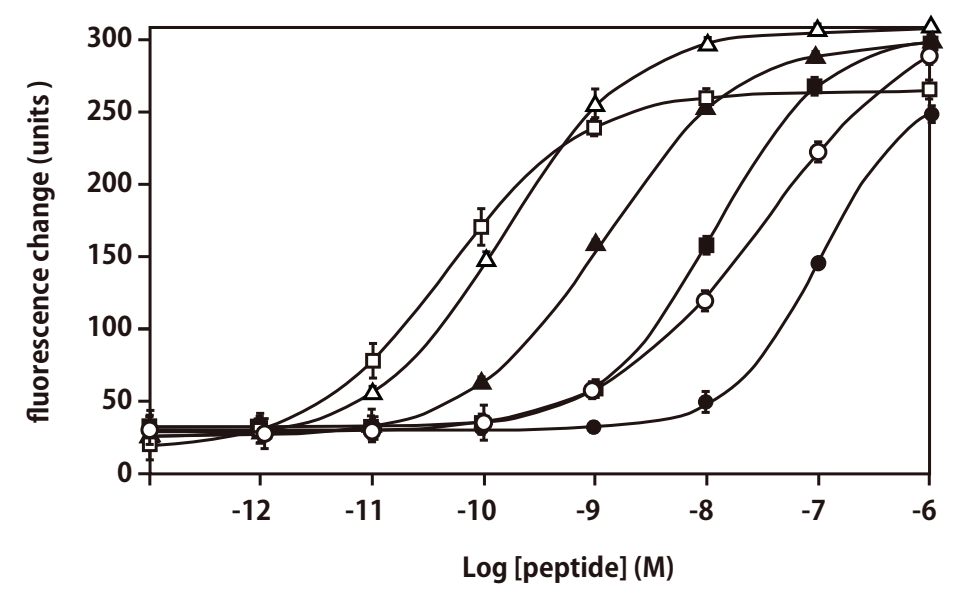

O CCHamide-1

Non-C-terminal

amidated CCHamide-1

CCHamide-2

Non-C-terminal

amidated CCHamide-2

$\Delta$ long form CCHamide-2

Non-C-terminal amidated

long form CCHamide-2

FIGURE 3 | Pharmacological characterization of synthetic peptides using CG30106 or CG14593 stably expressed in CHO cells. (A,B)

Concentration-response relationships of changes in $\left[\mathrm{Ca}^{2+}\right]_{\mathrm{i}}$ for $\mathrm{CCHamide-1}$ (open circle) and CCHamide-2 (open square), in CHO-CG30106 cells (A) or CHO-CG14593 cells (B). (C,D) Concentration-response relationships of changes in $\left[\mathrm{Ca}^{2+}\right]_{i}$ for various peptides, $\mathrm{CCHamide-1}$ (open circle), and
CCHamide-2 (open square) in CHO-CG30106 cells (C) or CHO-CG14593 cells (D). Non-C-terminal amidated CCHamide-1 (filled circle), non-C-terminal amidated $\mathrm{CCH}$ amide-2 (filled square), long-form CCHamide-2 (open triangle), and non-C-terminal amidated long-form CCHamide-2 (filled triangle). Each symbol on the line graph represents the mean \pm SEM of data from six replicates for each experiment. 


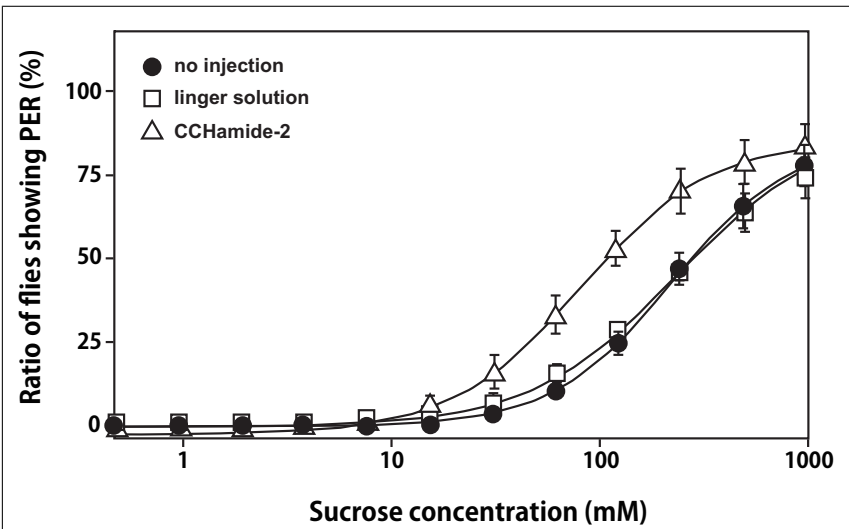

FIGURE 4 | Effect of CCHamide-2 on PER of the blowfly. Sigmoidal curves show the sucrose concentration-PER relationship for three fly groups: no injection (closed circle), injection with linger solution (open square), and injection of $\mathrm{CCH}$ amide-2 (open triangle). Each symbol on the line graph represents the mean \pm SEM of data from five replicates for each experiment.

of CCHamide-2: the mean PER threshold decreased from $236 \mathrm{mM}$ (30 min after linger solution injection) to $77.2 \mathrm{mM}$ (30 min after CCHamide-2 injection; $p<0.05$ ). In contrast, no difference was observed between the mean PER threshold without any injection and $30 \mathrm{~min}$ after linger solution injection (222 and $236 \mathrm{mM}$, respectively, $p>0.05$ ).

\section{DISCUSSION}

In this study, we biochemically purified 2 Drosophila peptides (CCHamide-1 and CCHamide-2) as endogenous ligands for Drosophila GPCRs CG30106 and CG14593. Recently, Hansen etal. (2011) independently identified these peptides from genome database and reported that synthetic CCHamide1 and CCHamide-2 potently activated CHO/G-16 cells expressing recombinant CG30106 and CG14593. Then, Reiher et al. (2011) characterized CCHamide- 1 and CCHamide-2 from the Drosophila midgut by capillary offline RP-HPLC coupled with MALDI-TOF MS/MS. Our biochemical characterization, however, for the first time, demonstrated three forms of CCHamide-2. The CCHamide2 preproprotein is 136 amino acid residues long and contains three forms of CCHamide-2. The CCHamide-1 preproprotein is 182 amino acid residues long and contains one form of CCHamide-1. Pharmacological characterization by using $\mathrm{CHO}$ cells expressing GPCRs indicated that CCHamide-1 had a high potency for activating recombinant CG30106, but CCHamide-2 rather potently activated CG30106. In contrast, CCHamide-2 had a high potency for activating recombinant CG14593, but CCHamide-1 rather potently activated CG14593. Long-form CCHamide-2 and CCHamide-2 shared a highly similar potency for activating recombinant CG14593. Although we did not generate synthetic KKGCQAYGHVCYGGH-NH 2 , it is predicted to have a high potency similar to that of other forms of CCHamide-2 for activating CG14593 because of the relationship between the amount of purified peptide and the specific activity. KKGCQAYGHVCYGGH$\mathrm{NH}_{2}$ (P4) and AQQSQAKKGCQAYGHVCYGGH-NH 2 (P2) may be incomplete processing intermediates of GCQAYGHVCYGGH$\mathrm{NH}_{2}$ (P3), originating from two alternative signal peptide cleavage sites and incomplete KK prohormone convertase processing. The quantity of the purified peptide could not be accurately measured at the time of the experiments. Because the gel filtration fractions with particularly high activity were separated by CM-ion-exchange HPLC at pH 6.5, we did not purify all peptides for their receptors from the flies collected. However, we purified peptide KKGCQAYGHVCYGGH-NH $\mathrm{N}_{2}$ (P4) > AQQSQAKKGCQAYGHVCYGGH$\mathrm{NH}_{2}$ (P2) > GCQAYGHVCYGGH-NH$H_{2}$ (P3) in amount. Therefore, in this study, we cannot conclude whether P4 and P2 are mature peptides or incomplete processing intermediates of P3. Because both CCHamide-1 and CCHamide-2 have a disulfide bond and a YGH motif, the disulfide bond is predicted to be an important structure for GPCR activation. Additionally, both peptides have a GXG-NH$H_{2}$ motif at the C-terminus. Therefore, we synthesized non-C-terminal amidated peptides to determine whether the C-terminal amide was necessary for the activation of each receptor. These results show that these peptides are considered to require both disulfide bonds and Cterminal amides to activate their respective GPCRs. Because we biochemically purified these ligands for the receptors by using the reverse pharmacological technique, we propose that no further modified forms or unknown ligands exist for these receptors in the fruit fly. CCHamide-1 is a cognate ligand for CG30106 and the three forms of CCHamide- 2 are cognate ligands for CG14593.

BRS-3 is a mammalian orphan receptor (Ohki-Hamazaki et al., 1997). Drosophila CG30106 and CG14593 belong to the BRS-3 phylogenetic subgroup (Hewes and Taghert, 2001). To provide new insights into the search for BRS-3 ligands, we examined whether CCHamides activate BRS-3, but we did not find any effect (data not shown).

CCHamide-1 and CCHamide-2 have been shown to be expressed predominantly in the brain and midgut (by FlyAtlas; http://www.flyatlas.org/; Chintapalli et al., 2007). In addition, CCHamide-1 and CCHamide-2 have been detected in the nervous system and midgut in a mass spectrometry study performed by Reiher etal. (2011). Therefore, CCHamides are suggested to be brain-gut peptides in insects. It is generally accepted that brain-gut peptides regulate feeding behavior in mammals (Williams etal., 2001). These peptides include neuropeptide Y, peptide YY, gastrin-releasing peptide, vasoactive intestinal peptide, adrenomedullin, cholecystokinin, galanin, glucagon-like peptide1, and neuromedin U (Zimanyi et al., 1998; Beck, 2001). In addition, CCHamide- 2 was distributed in the larval fat body (by FlyAtlas). The insect fat body is a functional counterpart of the mammalian adipose tissue and liver (Gutierrez et al., 2007). In mammal adipose tissue, leptin and adiponectin are important for feeding modulation. Therefore, we evaluated the effects of CCHamide on feeding by using the PER test in the blowfly Phormia regina. In flies and certain other insects, the PER test has long been used to investigate behavioral sensitivity to phagostimulative tastes (Nisimura et al., 2005). Flies extend their proboscis when the contact chemosensilla on their labella detects sweetness of sugar above a certain threshold concentration. Thus, we estimated the appetite or feeding motivation of the flies on the basis 
of the PER test for sucrose, in which the threshold concentration of sucrose was evaluated as an indicator of feeding sensitivity. The injection of CCHamide-2 decreased the threshold for feeding on a sucrose solution. These data suggest that CCHamide-2 stimulates the feeding motivation of flies. Indeed, administration of CCHamide-2 significantly increased the sucrose intake (Hiraguchi et al., paper in preparation). In the presence of amino acids in the diet, target-of-rapamycin complex 1 (TORC1) signaling in fat cells generates a positive messenger that is released into the hemolymph (Colombani et al., 2003). This signal reaches the brain insulin-producing cells (IPCs), where it remotely controls the secretion of Drosophila insulin-like peptides (Dilp). Insulinlike peptides couple growth, metabolism, longevity, and fertility with changes in nutritional availability (Géminard et al., 2009). If CCHamide is a humoral factor that is secreted from the fat body like unpaired 2, it may play an important role in the modulation of nutrient status and growth (Rajan and Perrimon, 2012). Mice lacking functional BRS-3 develop metabolic defects and obesity (Ohki-Hamazaki et al., 1997). Therefore, the natural ligand of

\section{REFERENCES}

Beck, B. (2001). KO's and organisation of peptidergic feeding behavior mechanisms. Neurosci. Biobehav. Rev. 25, 143-158.

Brody, T., and Cravchik, A. (2000). Drosophila melanogaster G proteincoupled receptors. J. Cell Biol. 150, 83-88.

Chintapalli, V. R., Wang, J., and Dow, J. A. (2007). Using FlyAtlas to identify better Drosophila melanogaster models of human disease. Nat. Genet. 39, 715-720.

Civelli, O., Reinscheid, R. K., Zhang, Y., Wang, Z., Fredriksson, R., and Schiöth, H. B. (2012). G proteincoupled receptor deorphanizations. Annu. Rev. Pharmacol. Toxicol. doi: 10.1146/annurev-pharmtox010611-134548 [Epub ahead of print].

Colombani, J., Raisin, S., Pantalacci, S., Radimerski, T., Montagne, J., and Leopold, P. (2003). A nutrient sensor mechanism controls Drosophila growth. Cell 114, 739-749.

Géminard, C., Rulifson, E. J., and Léopold, P. (2009). Remote control of insulin secretion by fat cells in Drosophila. Cell Metab. 10, 199-207.

Gutierrez, E., Wiggins, D., Fielding, B., and Gould, A. P. (2007). Specialized hepatocyte-like cells regulate Drosophila lipid metabolism. Nature 445, 275-280.

Hewes, R. S., and Taghert, P. H. (2001). Neuropeptides and neuropeptide receptors in the Drosophila melanogaster genome. Genome Res. 11, 1126-1142.
Hansen, K. K., Hauser, F., Williamson, M., Weber, S. B., and Grimmelikhuijzen, C. J. (2011). The Drosophila genes CG14593 and CG30106 code for G-protein-coupled receptors specifically activated by the neuropeptides CCHamide-1 and CCHamide-2. Biochem. Biophys. Res. Commun. 404, 184-189.

Ida, T., Takahashi, T., Tominaga, H., Sato, T., Kume, K., Ozaki, M., et al. (2011a). Identification of the novel bioactive peptides dRYamide- 1 and dRYamide-2, ligands for a neuropeptide Y-like receptor in Drosophila. Biochem. Biophys. Res. Commun. 410, 872-77.

Ida, T., Takahashi, T., Tominaga, H., Sato, T., Kume, K., YoshizawaKumagaye, K., et al. (2011b). Identification of the endogenous cysteine-rich peptide trissin, a ligand for an orphan $G$ proteincoupled receptor in Drosophila. Biochem. Biophys. Res. Commun. 414, 44-48.

Majumdar, I. D., and Weber, H. C. (2012). Biology and pharmacology of bombesin receptor subtype-3. Curr. Opin. Endocrinol. Diabetes Obes. 19, 3-7.

Marshall, I. C., Boyfield, I., and McNulty, S. (2005). Ratiometric $\mathrm{Ca}^{2+}$ measurements using the FlexStation ${ }^{\circledR}$ Scanning Fluorometer. Methods Mol. Biol. 312, 119-124.

Nisimura, T., Seto, A., Nakamura, K., Miyama, M., Nagao, T., Tamotsu, S., et al. (2005). Experiential effects of appetitive and nonappetitive odors on feeding behavior in the blowfly, Phormia regina: a putative role for

BRS-3 is expected to be a prominent inhibitor of appetitive behavior. The difference between CCHamide and the unknown ligand for BRS-3 with regard to feeding behavior is not clear. Further studies should de-orphanize BRS-3 by considering CCHamide by using bioinformatics or antibodies for CCHamide or Drosophila GPCRs.

\section{ACKNOWLEDGMENTS}

We thank Kaori Shirouzu, Masako Naito, and Eri Iwamoto for their technical assistance. This work was financially supported in part by the Improvement of Research Environment for Young Researchers Program of the Ministry of Education, Culture, Sports, Science and Technology; a grant for Scientific Research on Priority Areas from the University of Miyazaki; grants-in-aid from the Ministry of Education, Culture, Sports, Science and Technology, Japan; the Program for Promotion of Basic Research Activities for Innovative Bioscience (PROBRAIN); Suzuken Memorial Foundation; Shimadzu Scientific Foundation; and Uehara Memorial Foundation.

tyramine in appetite regulation. $J$. Neurosci. 25, 7507-7516.

Ohki-Hamazaki, H., Watase, K. Yamamoto, K., Ogura, H., Yamano, M., Yamada, K., et al. (1997). Mice lacking bombesin receptor subtype-3 develop metabolic defects and obesity. Nature 390, 165-169.

Rajan, A., and Perrimon, N. (2012). Drosophila cytokine unpaired 2 regulates physiological homeostasis by remotely controlling insulin secretion. Cell 151, 123-137.

Reiher, W., Shirras, C., Kahnt, J., Baumeister, S., Isaac, R. E., and Wegener, C. (2011). Peptidomics and peptide hormone processing in the Drosophila midgut. J. Proteome Res. 10, 1881-1892.

Roller, L., Yamanaka, N., Watanabe, K., Daubnerova, I., Zitnan, D., Kataoka, H., et al. (2008). The unique evolution of neuropeptide genes in the silkworm Bombyx mori. Insect Biochem. Mol. Biol. 38, 11471157.

Vassilatis, D. K., Hohmann, J. G., Zeng, H., Li, F., Ranchalis, J. E., Mortrud, M. T., et al. (2003). The $\mathrm{G}$ protein-coupled receptor repertories of human and mouse. Proc. Natl. Acad. Sci. U.S.A. 100, 4903 4908.

Williams, G., Bing, C., Cai, X. J., Harrold, J. A., King, P. J., and Liu, X. H. (2001). The hypothalamus and the control of energy homeostasis: different circuits, different purposes. Physiol. Behav. 74, 683-701.

Zimanyi, I. A., Fathi, Z., and Poindexter, G. S. (1998). Central control of feeding behavior by neuropeptide Y. Curr. Pharm. Des. 4, 349-366.

Conflict of Interest Statement: The authors declare that the research was conducted in the absence of any commercial or financial relationships that could be construed as a potential conflict of interest.

Received: 25 September 2012; accepted: 14 December 2012; published online: 31 December 2012.

Citation: Ida T, Takahashi T, Tominaga H, Sato T, Sano H, Kume K, Ozaki $M$, Hiraguchi T, Shiotani H, Terajima $S$, Nakamura $Y$, Mori K, Yoshida $M$, Kato J, Murakami N, Miyazato M, Kangawa K and Kojima M (2012) Isolation of the bioactive peptides CCHamide-1 and CCHamide-2 from Drosophila and their putative role in appetite regulation as ligands for $G$ protein-coupled receptors. Front. Endocrin. 3:177. doi: 10.3389/fendo.2012.00177

This article was submitted to Frontiers in Neuroendocrine Science, a specialty of Frontiers in Endocrinology.

Copyright (C) 2012 Ida, Takahashi, Tominaga, Sato, Sano, Kume, Ozaki, Hiraguchi, Shiotani, Terajima, Nakamura, Mori, Yoshida, Kato, Murakami, Miyazato, Kangawa and Kojima. This is an open-access article distributed under the terms of the Creative Commons Attribution License, which permits use, distribution and reproduction in other forums, provided the original authors and source are credited and subject to any copyright notices concerning any thirdparty graphics etc. 